\title{
Verbal Communications Related to Self-Disclosure and Interpersonal Relationships in Facebook Users
}

\author{
Shih-Hsiung Liu ${ }^{1}$ \\ ${ }^{1}$ Center for Teacher Education, National Changhua University of Education, Taiwan \\ Correspondence: Shih-Hsiung Liu, Center for Teacher Education, National Changhua University of Education, \\ No.1, Jin-De Road, Changhua, Taiwan. Tel: 88-64-723-2105. E-mail: shsiung@cc.ncue.edu.tw
}

\author{
Received: January 5, 2015 Accepted: June 24, 2015 Online Published: August 18, 2015 \\ doi:10.5539/ass.v11n22p81 URL: http://dx.doi.org/10.5539/ass.v11n22p81
}

\begin{abstract}
This study generalized the verbal communications of college students who use Facebook to contact friends and identified the detailed content of the verbal communications that predict interpersonal relationships in real life. Initially, 300 Taiwan college students were interviewed about their Facebook use, and verbal communications were divided into six categories. Two verbal communications were classified as verbal actions with self-disclosure due to their reference to personal thoughts, feelings and emotions: "sharing personal experiences", and "disclosing private emotions". The remaining four were classified as verbal actions with non-self-disclosure. Afterward, by developing the questionnaire items for verbal communications and interpersonal relationships, the study conducted a validated survey of 477 Taiwanese college students during April, 2013 to June, 2013. The study shows that students use verbal actions for non-self-disclosure more frequently than for self-disclosure when using Facebook to contact friends. Another finding is that "giving emotional encouragements" and "delivering public information" are the predictors of positive interpersonal relationships. The study contributes to the literature by specifically showing that, compared to interpersonal relationships only impacted by emotional verbal communications, verbal communications related to psychological needs or useful and delivery of original information on Facebook, enhance interpersonal relationships.
\end{abstract}

Keywords: verbal communication, interpersonal relationships, self-disclosure, Facebook use

\section{Introduction}

The use of Facebook for social networking has increased globally. An obvious reason for using Facebook is to create social relationships and to reinforce pre-existing friendships with others who are already known in real life. Many studies have identified that using Facebook can facilitate social relationships with friends (Mesch \& Talmud, 2006; Park, Lee, \& Kim, 2012; Subrahmanyam, Reich, Waechter, \& Espinoza, 2008). Through communication verbally, seeking and receiving individual supports usually happen and simultaneously increase commitment to the relationships. Kelley, Berscheid, Christensen, Harvey, Huston, Levinger, et al. (1983) described an interpersonal relationship as a situation in which the emotions, thoughts, and behaviors of people are mutually and causally interconnected. The many benefits derived from interpersonal relationships and social groups range from health improvement, access to expertise, and emotional support. As people increasingly incorporate Facebook into their daily experience, they may undergo changes in their personal behavior and interpersonal relationships. Therefore, studies are needed to improve understanding of the nature of Facebook use, especially on content of interaction, and its effect on interpersonal relationships in real life.

In addition to lurking as well as playing games, many activities are available to Facebook users. Subrahmanyam, et al. (2008) indicated that the most common activities of Facebook users are reading comments, writing comments, and responding to comments/messages. These activities of reading, writing and responding are similar to verbal communications in real life in contrast to non-verbal communications, which are the sending and receiving of information using gestures, expressions, and body movements rather than words. When a person transfers a message to someone by verbal actions and ensures that the message is received by the receiver, a verbal communication just happens, not necessarily with responses to the person, like a speaker talking to audiences. Moreover, verbal communications not only involve the delivery of spoken words to others, but also imply the disclosure of personal feelings and emotions. Along with interacting with known friends online, verbal communications on Facebook can be defined as an act of sharing thoughts, feelings and emotions through the 
use of Facebook. Studies of the impact of Facebook on social relationships apparently agree that verbal communication has a critical impact on interpersonal relationships.

By enabling verbal communication by Internet, Facebook provides a mean for individuals to present themselves to others. This process of making one self-known to others is called self-disclosure (Jourard \& Lasakow, 1958, p. 91). According to Derlega, Metts, Petronio and Margulis (1993, p. 1), self-disclosure can be defined as "what individuals verbally reveal about themselves, including thoughts, feelings, and experiences, to others". Self-disclosure refers to an interaction between at least two individuals, one of whom intends to divulge personal information to another (Greene, Derlega, \& Mathews, 2006, p. 411). In other words, the difference between self-disclosure and non-self-disclosure in verbal communications is the reference to personal thoughts, feelings and emotions. Self-disclosure processes are important aspects of relational development during in-person communications (Derlega, Winstead, Wong, \& Greenspan, 1987). New technology, and in particular the Internet, might well change the demands upon people to disclose personal information (Joinson \& Paine, 2007). Chen and Marcus (2012) reviewed the literature on self-disclosure and suggested that individuals tend to present their true or authentic selves to others. Since people are more willing to make self-disclosures on the Internet than in the real life situation (McKenna, Green, \& Gleason, 2002), Facebook can facilitate people in voluntarily expressing their thoughts, emotions, beliefs, and attitudes towards life, especially to known friends.

Moreover, people who communicate on Facebook use a one-to-many style in which they create content and disseminate content to their friends. College students can communicate privately by Facebook while they are more likely to post messages on walls than to send private messages (Pempek et al., 2009). According to a study by Pempek et al. (2009), the content of Facebook messages sent and received in wall posts by college students included "referring to inside jokes", "catching up", "making plans to get together", "commenting on profile or pictures", "just saying hello", "telling a friend about a past event", "talking about courses", and "gossiping about others". However, the above categories do not clearly reveal the nature of self-disclosure.

According to Laurenceau, Barrett and Pietromonaco (1998), self-disclosure may be emotional or factual. Both types explain the above categorized postings by college students. Emotional self-disclosure is associated with increased closeness (Reis \& Shaver, 1988) and is a stronger predictor of intimacy compared to factual self-disclosure (Laurenceau et al., 1998). Oulasvirta, Lehtonen, Kurvinen and Raento (2010) also distinguished between self-disclosure and non-self-disclosure by analyzing how micro-blog users respond when they share daily experiences with others. Non-self-disclosure includes the sharing of non-personal information such as facts and news. The above perspectives, forming a theoretical rationale, apparently raise the possibility that emotional self-disclosure, not factual self-disclosure, through verbal communications on Facebook benefits interpersonal relationships in real life.

Studies suggested that initiating interpersonal relationships and developing close relationships are the two main goals of using social networking websites (Kwak, Choi, \& Lee, 2014; Subrahmanyam et al., 2008). However, studies have suggested that Facebook use is negatively related to competence in forming interpersonal relationships (Jenkins-Guarnieri, Wright, \& Hudiburgh, 2012) whereas emotional support on Facebook may be an integral part of promotion of intimate relationships (Bevan, Pfyl, \& Barclay, 2012; Radmacher \& Azmitia, 2006). That is, verbal communications involving emotion (i.e. emotional self-disclosure and its frequency) during Facebook use must be analyzed to understand the associations between Facebook use and interpersonal relationships. That is, the effects of different verbal communications on Facebook, e.g., self-disclosure and non-self-disclosure, and their detailed actions should be compared in terms of their effects on interpersonal relationships.

In sum, although previous studies suggest that Facebook can facilitate social relationships in college students, few studies have focused on the issues of self-disclosures in verbal communications. Additionally, no studies have clearly identified the detailed content of verbal communications that facilitate interpersonal relationships. Therefore, the purposes of this study are to generalize the verbal communications of college students when using Facebook to contact friends and to identify the verbal communications that predict interpersonal relationships in real life. Two research questions are addressed.

1. What verbal communications do college students make when using Facebook to contact friends? Do non-self-disclosure and self-disclosure differ in frequency of verbal communications?

2. What detailed content of verbal communications predict interpersonal relationships in Facebook user?

\section{Methods}

This study was divided into two parts. To explore the detailed content of verbal communications by college 
students, an interview technique was used to collect their descriptions about using Facebook to contact friends. The data were then analyzed and categorized into different verbal communications based on the contents of exchanging thoughts or sharing feelings and emotions. Secondly, the description of each verbal communication was used to develop questionnaire items. A survey was then performed to categorize the verbal communications and interpersonal relationships of the college students.

\subsection{Interviews}

The researcher recruited three graduate students who had at least 5 years' experience using Facebook and trained them to perform the interviews. The study developed three open-ended questions for the interview. Five professors with expertise in higher education and communication were invited to comment on the questions. According to their suggestions, the revised questions were 1). On average, how much time do you spend daily using Facebook to contact friends, including lurking in Facebook walls? (If the answer was less than 10 minutes, the interview ended.) 2). Except for lurking, what have you written on Facebook walls? (The interviewees were encouraged to give more than one answer.) 3). According to the above responses, please describe why you wrote that. The first question was aimed at identifying the appropriateness of the invited interviewees in this study based on data in the literature showing that college students spend an average of at least 10 minutes daily on Facebook use. The main study data about verbal communications was collected by the second question. The third question identified situations when verbal communications were made (the response in the second question) for purposes of coding and categorizing the study data.

Each interview was performed in 10 minutes in a classroom, campus path, school restaurant, or student dorm through random invitation. From February to March, 2013, 300 college students, consisting of 154 male and 146 female from a university in central Taiwan, voluntarily participated in face-to-face interviews after the interviewees' rights were notified, and all responses were immediately recorded. The researcher and interviewers discussed and analyzed data every week to form temporary codes and to identify patterns of verbal communications related to non-self-disclosure and self-disclosure. As the interview data accumulated, the data were compared, and codes were revised. Finally, patterns of verbal communications emerged.

\subsection{Questionnaires}

\subsubsection{Verbal Communication Scale}

The verbal communication scale in the questionnaire used the patterns of verbal communications identified in the interview and then developed scale items by referring to descriptions by the respondents. The initial items were revised by five professors with expertise in higher education and communication. Factor analysis was used to analyze each factor (pattern) structure of verbal communications. Cronbach alpha coefficients were then calculated. The details of data collection are described further in the Results section.

\subsubsection{Interpersonal Relationship Scale}

The interpersonal relationships scale was based on a scale developed in a study by Tsai (2000), which also analyzed a Taiwan population. Tsai determined that interpersonal relationships exist between any two or more persons who interact and fulfill one or more psychological or emotional needs. Tsai also indicated that a strong interpersonal relationship requires the individuals to have a caring attitude, to express concern about others, to listen actively to the needs of others, to be effective at observing others, and to be effective at interacting with others and understanding their situation, feelings, and motives. The present study developed 15 items for interpersonal relationship in real life based on the four aspects described above: actively expressing concern (six items), positive listening (four items), sincere interaction (three items), and effective communication (two items). An example item for actively expressing concern is as follows: "When a friend becomes silent, you try to chat with him/her." An example item for positive listening is as follows: "When a friend is sharing his/her personal information, you listen attentively." An example item for sincere interaction is as follows: "When a friend asks you to do him/her a favor by contacting others, you pay attention to the details." An example item for effective communication is as follows: "When chatting with friends, you never lie."

The initial items were revised by five experts as mentioned above. Out of 102 questionnaires distributed in a pilot test in college students, two incomplete questionnaires were eliminated. Therefore, 100 valid questionnaires were collected. The analytical results for the interpersonal relationship questionnaire survey performed in the pilot study revealed that equality of means of each item for item analysis reached the significant level $(p<.05)$, and correlations coefficients between each item and sum scores ranged from 0.462 to $0.756(r>.03, p<.05)$. The Cronbach alpha coefficient for the interpersonal relationships scale was 0.889 . That is, the questionnaire was appropriate for data collection in this study. 


\subsection{Sample}

While Facebook is popular with all Internet users, it is even more so with college students. Based on data from CheckFacebook.com, most Taiwan college students and graduates aged 18-24 years have used Facebook. They spend more time on Facebook than other websites according to a Taiwanese college student study by Peng and Juan (2011). Generally, Facebook use has become pervasive in Taiwan university life.

Stratified random cluster sampling was used for data collection. Statistical data from the Ministry of Education (2013) of Taiwan indicate that Taiwan has roughly 1,038,000 college students enrolled in 120 universities and 28 colleges. In Cohen, Manion, and Morrison (2007), a sample size of 384 college students was considered adequate at the 0.95 confidence level and $5 \%$ confidence intervals. Here, the study sample comprised 580 college students representing 22 Taiwanese universities and colleges. Each school received 15-60 questionnaires based on the number of students. Students who had experience using Facebook to contact friends were invited to complete the questionnaire from April, 2013 to June, 2013. Out of 496 questionnaires retrieved, 477 questionnaires were valid.

\section{Results}

Table 1 shows the six verbal communications revealed by the analysis of the interview data. Four verbal communications, "inviting others to play Facebook game", "forwarding postings by others", "delivering public information", and "giving emotional encouragements", were classified as non-self-disclosure communication because they did not express individual feelings and emotions. The remaining two verbal actions related to self-disclosure during verbal communications were "sharing personal experiences", and "disclosing private emotions".

In terms of "inviting others to play Facebook game", two common responses were asking friends for help and inviting invite friends to join Facebook games such as "Candy Crush". "Forwarding postings by others" is a verbal communication involving duplication of postings by other. Respondents indicated that they forwarded posts that were funny or that prompted reflection or fear. "Delivering public information" was common communication when announcing public affairs in a group such as a student organization. This pattern also included useful and original information about social activities, regulations and emergency help. Additionally, the respondents indicated that they tried to be encouraging when they read sad and frustrating posts by their friends. Wishing friends a happy birthday was also common. The respondents indicated that the verbal interactions on Facebook easily give emotional encouragements to friends, unlike real life contacts, which they found more difficult due to shyness. The above verbal actions were categorized as "giving emotional encouragements". All four of the above verbal communications involved information rather than personal feelings and emotion. Thus, the two verbal communications were categorized as non-self-disclosures.

Table 1. Verbal communications related to non-self-disclosure and self-disclosure during Facebook use

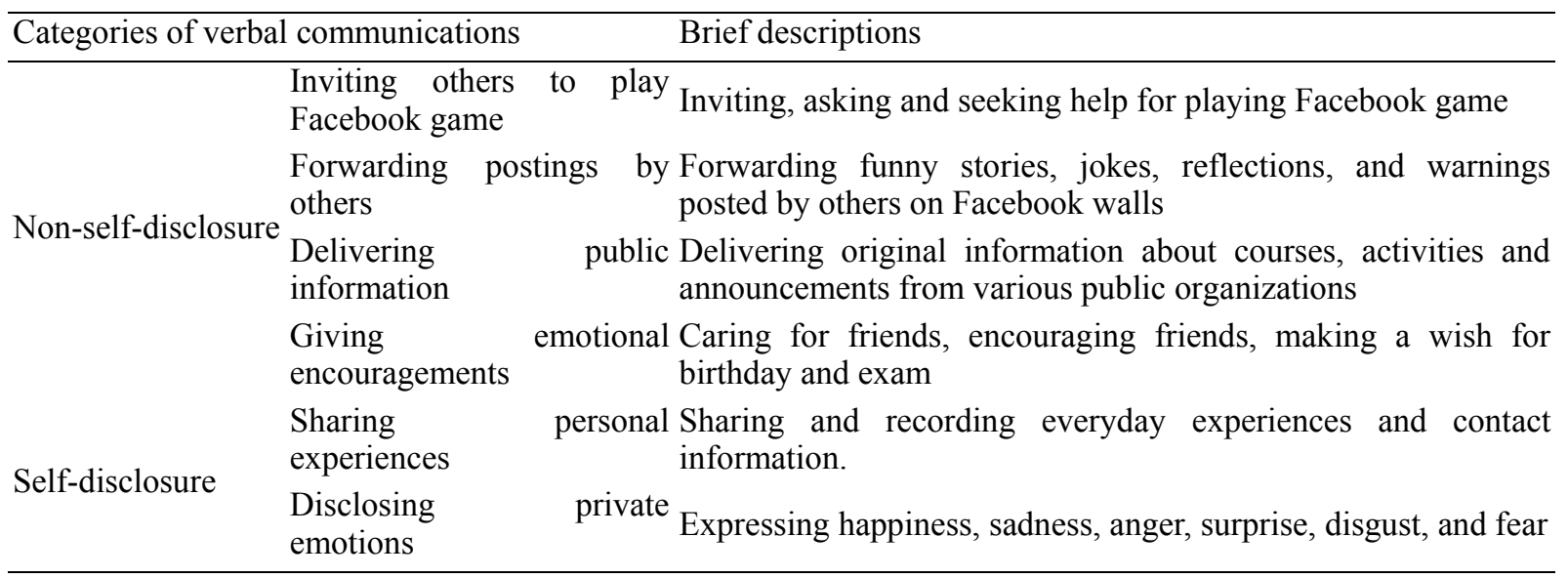

In contrast, verbal actions based on personal-related contents were classified as self-disclosures. "Sharing personal experiences" was proposed by almost all interviewees. Except for check-in on Facebook wall, interviewees usually shared their daily experiences and travel experiences by posting photos. Finally, "disclosing private emotions" was a verbal action related to sharing personal thoughts, feelings and moods. Respondents 
mentioned that they expressed anger, frustration, and happiness in posts because they wanted to obtain feedback from friends and to confirm pre-existing friendships. Of course, another reason was to express personal emotions. Some interviewees stated that their reason for posting was not to contact friends, but to write about their own thoughts and feelings. The above finding reveals that Facebook is a tool of self-disclosure in addition to facilitating social relationships with friends for college students.

Questionnaire items were further developed based on the analytical results for the above six verbal communications and the interviewee responses. The five professors were invited to confirm the above analytical results and to comment the questionnaire items. After further revision by the authors followed by an expert evaluation, another survey was performed. The subjects responded to each survey item on a five-point Likert scale ranging from 1 for "never" to 5 for "always."

For the 477 valid questionnaires, Table 2 shows the factor analysis results with means and standard deviations. The analytical results revealed that, for each factor, the Kaiser-Meyer-Oklin values (0.924) exceeded 0.6, and the Bartlett Test of Sphericity reached statistical significance, which supported the factorability of the correlation matrix. Six factors with eigenvalues $>1$ emerged from the rating analysis and accounted for more than $49.7 \%$ of the variance in data before rotation, and the responses had loadings of $>0.57$ on these factors. The Cronbach alpha coefficient ranged from 0.722 to 0.892 and was 0.937 for the total scale. That is, the questionnaire items were confirmed as appropriate for assessing the verbal communications by the college students surveyed in this study.

Notably, the study further compared the difference between sum scores of non-self-disclosure and that of self-disclosure by Independent-Sample $\mathrm{T}$ test which revealed a significant difference, $t=3.982, d f=471$, $p=000<.05$, non-self-disclosure (2.66) $>$ self-disclosure (2.56). That is, the college students performed more verbal actions for non-self-disclosure than for self-disclosure when using Facebook to contact friends.

Additionally, the analytical result reveals the means of each item on an interpersonal relationship scale, ranging from 3.22 to 4.13, superior to the median (3) on a five-point scale.

Moreover, a multiple regression analysis was conducted to examine the verbal communications that significantly predict the interpersonal relationships of college students. Firstly, the correlation coefficients between each verbal communication and interpersonal relationship were analyzed. Except for "inviting others to play Facebook game" $(r=0.053, p=0.246>0.05)$, the remaining five types of verbal communications reached statistical significance $(p<.05)$ in Pearson correlation analyses. The five verbal communications were then used as independent variables for multiple regression programs.

Two independent variables, "giving emotional encouragements" and "delivering public information", significantly contributed to explaining the interpersonal relationships of college students $(p=0.002<0.05)$. The remaining verbal communications, "forwarding postings by others" $(p=0.105>0.05, \beta=-0.084)$, "sharing personal experiences" $(p=0.144>0.05, \beta=-0.083)$ and "disclosing private emotions" $(p=0.881>0.05, \beta=0.008)$ did not reach statistical significance. The proportion of variance explained by the regression model was reflected by $R^{2}$ values of $15.9 \%$ for "giving emotional encouragements" and $1.7 \%$ for "delivering public information". The two variables jointly accounted for $17.6 \%$ of variances in interpersonal relationships. The $\beta$ coefficients are the standardized weights and indicated the relative importance of the independent variables. According to the $\beta$ coefficients obtained in the multiple regression model, the largest contributors to explaining interpersonal relationships was "giving emotional encouragements" $(\beta=0.313)$ followed by "delivering public information" $(\beta=0.155)$. Notably, "giving emotional encouragements" was a stronger predictor in this case compared to "delivering public information". Additionally, the $\beta$ coefficients for "giving emotional encouragements" and for "delivering public information" were both positive, which indicated that they positively predict interpersonal relationships for college students. Restated, as verbal actions related to "giving emotional encouragements" and "delivering public information" on Facebook communication increased, interpersonal relationships with friends were stronger.

\section{Conclusions and Discussion}

The study investigated verbal communications by college students when using Facebook and identified verbal communications that predict interpersonal relationships. Out of the six verbal communications generalized in this study, four were classified as non-self-disclosure verbal communications: "inviting others to play Facebook game", "forwarding postings by others", "delivering public information", and "giving emotional encouragements". The remaining two were classified as self-disclosure verbal communications since they involved expression of individual feelings and emotions to friends: "sharing personal experiences", and "disclosing private emotions". The study also showed that non-self-disclosure verbal actions were more common 
than self-disclosure verbal actions when using Facebook to contact friends. Another finding was that "giving emotional encouragements" and "delivering public information" are the predictors of positive interpersonal relationships of the college students.

Table 2. Mean scores and standard deviations of the items in six factors about verbal actions

\begin{tabular}{|c|c|c|}
\hline Factor 1: inviting friends to Facebook game & $M$ & $S D$ \\
\hline 27. inviting friends to play online games & 2.10 & 1.13 \\
\hline 28. asking others for resources needed for the game & 2.30 & 1.33 \\
\hline 29. posting high scores to find challengers & 1.67 & 1.05 \\
\hline 30. posting tips or strategies for winning a game to interact with others & 1.63 & 1.05 \\
\hline sub-total & 1.93 & 1.02 \\
\hline Factor 2: forwarding postings by others & $M$ & $S D$ \\
\hline 1. posting multimedia or texts of personal interest & 2.89 & 1.06 \\
\hline 2. posting multimedia or texts that can help others & 2.68 & 1.06 \\
\hline 3. posting online tests such as psychological tests & 1.87 & 0.96 \\
\hline 4. posting information provided on other websites & 3.06 & 1.09 \\
\hline 5. posting articles about vital issues or important news from an electronic newspaper & 2.44 & 1.13 \\
\hline sub-total & 2.59 & 0.83 \\
\hline Factor 3: delivering public information & $M$ & $S D$ \\
\hline 13. posting information about assignments or reports for discussion by clubs & 3.75 & 1.08 \\
\hline 14. posting public announcements and regulations & 3.40 & 1.14 \\
\hline 15. posting meaningful life information to popularize new ideas & 2.45 & 1.09 \\
\hline 16. posting emergency information to notify others & 2.23 & 1.11 \\
\hline sub-total & 2.96 & 0.82 \\
\hline Factor 4: giving emotional encouragements & $M$ & $S D$ \\
\hline 17. posting congratulations on walls on a particular day & 3.64 & 1.06 \\
\hline 18. expressing concern on walls & 3.05 & 1.14 \\
\hline 19. interacting with others to improve relationships & 2.81 & 1.08 \\
\hline 20. organizing class reunions or class trips on Facebook and inviting friends to join clubs & 3.07 & 1.15 \\
\hline 21. replying to others actively to facilitate relations & 2.98 & 1.00 \\
\hline sub-total & 3.11 & 0.83 \\
\hline Factor 5: sharing personal experiences & $M$ & $S D$ \\
\hline 6. sharing personal work status & 2.52 & 1.17 \\
\hline 7. sharing personal photos of life & 3.33 & 1.07 \\
\hline 8. sharing what you are doing or where you are & 2.88 & 1.07 \\
\hline 9. sharing trivial matters in your daily life & 2.97 & 1.10 \\
\hline 10. describing personal life events & 2.53 & 1.07 \\
\hline 11. offering latest personal information for contacts & 2.13 & 1.07 \\
\hline 12. posting information about your own image & 1.71 & 1.03 \\
\hline sub-total & 2.58 & 0.76 \\
\hline Factor 6: disclosing private emotions & $M$ & $S D$ \\
\hline 22. showing your moods on your wall & 2.98 & 1.12 \\
\hline 23. posting your comments about lectures, speeches and activities & 2.45 & 1.10 \\
\hline 24. disclosing information that you would not discuss with parents or teachers & 2.40 & 1.14 \\
\hline 25. posting your plans or expectations for the future & 2.38 & 1.10 \\
\hline 26. describing difficulties or disturbance that you face & 2.54 & 1.14 \\
\hline sub-total & 2.55 & 0.90 \\
\hline
\end{tabular}


Although Facebook was never intended to substitute for face-to-face communication, Facebook use has become pervasive. Given the original intent of Facebook, i.e., to build better pathways for sharing between people who already know each other in the real world, the issue of self-disclosure should be explored. As mentioned by Mckenna et al. (2002) and Joinson and Paine (2007), people are more willing to make self-disclosures to friends on the Internet than in real life. Internet technology provides an easy, convenient, and quick way for college students to share personal information, obtain feedback, ask for help and get assistance (Reis \& Shaver, 1988; Derlega et al., 1993). The dynamics of Facebook also enable individuals to talk about themselves to groups of friends or followers. However, interestingly, the findings in this study showed that the college students do not tend to make self-disclosures when using Facebook to contact friends. According to Wilson, Gosling, and Graham (2012), Facebook users gradually become aware of privacy issues and begin disclosing personal information in more restrictive ways. Self-disclosure may be influenced by security concerns (Chang \& Heo, 2014). Chen and Marcus (2012) found that university students selectively used privacy settings to control their self-presentation on social network sites. Notably, students may increasingly leave Facebook because they feel embarrassed when their timeline walls and photographs also being viewed by their parents who desire to join them, according to an across countries study by Miller (2013). Even though Facebook's status update box asks "what's on your mind," prompting users to disclose information, Facebook users did not necessarily disclosure their personal information due to privacy concerns. This is why the non-self-disclosure verbal actions of college students were more common than the self-disclosure verbal actions when using Facebook to contact friends. Furthermore, by contrast to a study by Pempek, et al. (2009) who identified college students' common Facebook messages irrelative to self-disclosure, the current study further not only verifies the limitation of self-disclosure on Facebook, but also challenges a plausible argument that Facebook is characterized by high amounts of self-disclosure.

Moreover, although Facebook is now the largest social network in the world, a big social network does not ensure good interpersonal relationships. The number of friends may reach hundreds or even thousands (Dunbar, 2011), while the number is only a sociometric cue (Tong et al., 2008) rather than an indicator of actual friendships. As mentioned above, Facebook is clearly effective for enhancing interpersonal relationships with friends. This study confirmed that "giving emotional encouragements" and "delivering public information" on Facebook are the predictors of positive interpersonal relationships in college students.

The literature indicates that Facebook use is negatively related to competence in forming interpersonal relationships (Jenkins-Guarnieri et al., 2012) while emotional support may be an integral part of intimate relationships (Radmacher \& Azmitia, 2006). That is, not all verbal communications on Facebook necessarily benefit interpersonal relationships. The finding of this study verifies earlier reports that emotional support is associated with relationship development (Reis \& Shaver, 1998; Radmacher \& Azmitia, 2006). The college students analyzed in this study often used Facebook to encourage and console friends during times of frustration. Notably, college students often make a simple verbal action, e.g., using Facebook to wish their friends a happy birthday, to initiate and enhance mutual friendships. Interpersonal relationships involve an attitude of caring and expressing concern to others. A sincere and friendly manner enhances the establishment of interpersonal relationships. Thus, the above verbal actions may imperceptibly promote individual interpersonal relationships. For this reason, one of the six verbal communications, "giving emotional encouragements", predicts interpersonal relationships.

Interestingly, two verbal communications related to self-disclosure, "sharing personal experiences" and "disclosing private emotions", are not significantly associated with interpersonal relationships. Although the literature indicates that emotional self-disclosure has an important impact on relationship development in communities (Chen \& Marcus, 2012; Derlega et al., 1987; Laurenceau et al., 1998), this study showed that, if only personal information is expressed to others, e.g., "sharing personal experiences" and "disclosing private emotions", such self-disclosure does not enhance interpersonal relationships due to the lack of mutual care and satisfaction of psychological needs. Studies also suggest that Facebook users tend to be extraverted and narcissistic (Ljepava, Orr, Locke, \& Ross, 2013; Ryan \& Xenos, 2011), which is consistent with the Facebook effect mentioned by Zuckerberg, the founder of Facebook (Kipkpatrick, 2010). One indicator of narcissism is presenting self-generated content (Ong et al., 2011), and narcissism is characterized by a lack of interest in forming strong interpersonal relationships and an engagement in self-regulatory strategies to affirm the positive self-views (Campbell \& Foster, 2007). Thus, a reasonable conclusion is that a user who only presents self-generated content (i.e., "sharing personal experiences" and "disclosing private emotions") tends to be a narcissistic and may not have strong interpersonal relationships.

Additionally, of the four verbal communications with non-self-disclosure, "delivering public information" is the 
only predictor of interpersonal relationships. According to Zuckerberg (Kirkpatrick, 2010), the core value of Facebook is not just a way to share photos and events, but also a set of friend connections that has many applications. Although any information can be distributed on Facebook, this study found that not all postings benefit interpersonal relationships. According to Tsai (2000), interpersonal relationships exist between any two or more persons who interact and fulfill one or more psychological or emotional needs. Thus, any Facebook posting perceived as useful can gain attention and even identification. "Delivering public information" about public affairs in an organization with members who are college students may provide the students with useful and original information about regulations and interesting social activities. After delivery of the information, the receivers may affirm the information and further develop interpersonal relationships with senders. As discussed earlier, interacting with others, not just presenting self-generated content, is needed to promote development of interpersonal relationships. In contrast, "forwarding postings by others" only duplicates the postings of others and does not have psychological effects, which make it difficult to facilitate interpersonal relationships. The above observations indicate that, of the non-self-disclosure verbal communications, "delivering public information" predicts interpersonal relationships whereas "forwarding postings by others" does not.

This study identified six verbal communications. Of these, the verbal communications that mutually provide psychological needs and that are actually needed in daily life (e.g., the actions of giving emotional encouragements with others and delivering useful and original information to friends) can enhance interpersonal relationships for college students. The remaining verbal communications cannot, even though some college students self-disclose personal experiences that may be considered as narcissism.

\section{Implications}

The study contributes to the literature by specifically revealing that, compared to verbal communications made only for self-disclosure and interpersonal relationships impacted by emotional verbal communications, verbal communications related to psychological needs or useful and original information on Facebook enhances interpersonal relationships. Generally, Facebook facilitates the social relationships of college students; this study reveals more specific details compared to the previous literature.

One limitation of this study is the potential gap between the descriptions given by respondents during interviews and the actual messages they post on Facebook walls. Verbal communications differ because respondents may not accurately recall all written messages during interviews.

\section{Acknowledgments}

The research is financed by National Science Council of the Republic of China, Taiwan. No. NSC-102-2410-H-018-027.

\section{References}

Bevan, J. L., Pfyl, J., \& Barclay, B. (2012). Negative emotional and cognitive responses to being unfriended on Facebook: An exploratory study. Computers in Human Behavior, 28(4), 1458-1464. http://dx.doi.org/10. 1016/j.chb.2012.03.008

Chang, C. W., \& Heo, J. (2014). Visiting theories that predict college students' self-disclosure on Facebook. Computers in Human Behavior, 30, 79-86. http://dx.doi.org/10.1016/j.chb.2013.07.059

Chen, B., \& Marcus, J. (2012). Students' self-presentation on Facebook: An examination of personality and self-construal factors. Computers in Human Behavior, 28, 2091-2099. http://dx.doi.org/10.1016/j.chb.2012. 06.013

Derlega, V. J., Metts, S., Petronio, S., \& Margulis, S. T. (1993). Self-Disclosure. Newbury Park, CA: Sage.

Derlega, V. J., Winstead, B. A., Wong, P., \& Greenspan, M. (1987). Self-disclosure and relationship development: An attributional analysis. Interpersonal Processes: New Directions in Communication Research, 172-187.

Dunbar, R. (2011). How many friends can you really have? Spectrum, IEEE, 48(6), 81-83.

Greene, K., Derlega, V. J., \& Mathews, A. (2006). Self-disclosure in personal relationships. In A. L. Vangelisti, \& D. Perlman (Eds.), The Cambridge handbook of personal relationships (pp. 409-427). New York: Cambridge University Press. http://dx.doi.org/10.1017/CBO9780511606632.023

Hsu, C. W., Wang, C. C., \& Tai, Y. T. (2011). The closer the relationship, the more the interaction on Facebook? Investigating the case of Taiwan users. Cyber-Psychology, Behavior \& Social Networking, 14(7/8), 473-476. http://dx.doi.org/10.1089/cyber.2010.0267

Jenkins-Guarnieri, M. A., Wright, S. L., \& Hudiburgh, L. M. (2012). The relationships among attachment style, 
personality traits, interpersonal competency, and Facebook use. Journal of Applied Developmental Psychology, 33(6), 294-301. http://dx.doi.org/10.1016/j.appdev.2012.08.001

Joinson, A. N., \& Paine, C. B. (2007). Self-disclosure, privacy and the Internet. In A. Joinson, K. Y. A. McKenna, T. Postmes, \& U. D. Reips (Eds.), Oxford handbook of Internet psychology (pp. 237-252). Oxford, UK: Oxford University Press.

Jourard, S. M., \& Lasakow, P. (1958). Some factors in self-disclosure. Journal of Abnormal and Social Psychology, 56(1), 91-98. http://dx.doi.org/10.1037/h0043357

Kelley et al. (Eds.). (1983). Close relationships. NY: Freeman.

Kirkpatrick, D. (2010). The Facebook effect: The real inside story of Mark Zuckerberg and the world's fastest-growing company. London: Virgin

Kwak, K. T., Choi, S. K., \& Lee, B. G. (2014). SNS flow, SNS self-disclosure and post-hoc interpersonal relations change: Focused on Korean Facebook user. Computers in Human Behavior, 31, 294-304. http://dx. doi.org/10.1016/j.chb.2013.10.046

Laurenceau, J. P., Barrett, L. F., \& Pietromonaco, P. R. (1998). Intimacy as an interpersonal process: The importance of self-disclosure, partner disclosure, and perceived partner responsiveness in interpersonal exchanges. Journal of Personality and Social Psychology, 74(5), 1238-1251. http://dx.doi.org/10.1037/ 0022-3514.74.5.1238

Ljepava, N., Orr, R. R., Locke, S., \& Ross, C. (2013). Personality and social characteristics of Facebook non-users and frequent users. Computers in Human Behavior, 29(4), 1602-1607. http://dx.doi.org/10.10 16/j.chb.2013.01.026

McKenna, K. Y. A., Green, A. S., \& Gleason, M. E. J. (2002). Relationship formation on the Internet: What's the big attraction? Journal of Social Issues, 58, 9-31. http://dx.doi.org/10.1111/1540-4560.00246

Mesch, G., \& Talmud, I. (2006). Online friendship formation, communication channels, and social closeness. International Journal of Internet Science, 1(1), 29-44.

Miller, D. (2013). Facebook's so uncool, but it's morphing into a different beast. Retrieved from $\mathrm{http}$ //theconversation.com/facebooks-so-uncool -but-its-morphing-into-a-different-beast-21548

Ministry of Education. (2013). The website for education statistics. Retrieved March 14, 2013, from https://stats.moe.gov.tw

Ong, E. Y. L., Ang, R. P., Ho, J. C. M., Lim, J. C. Y., Goh, D. H., Lee, C. S., \& Chua, A. Y. K. (2011). Narcissism, extraversion and adolescents' self-presentation on Facebook. Personality and individual differences, 50(2), 180-185. http://dx.doi.org/10.1016/j.paid.2010.09.022

Oulasvirta, A., Lehtonen, E., Kurvinen, E., \& Raento, M. (2010). Making the ordinary visible in microblogs. Personal and Ubiquitous Computing, 14(3), 237-249. http://dx.doi.org/10.1007/s00779-009-0259-y

Park, N., Lee, S., \& Kim. J. H. (2012). Individuals' personal network characteristics and patterns of Facebook use: A social network approach. Computers in Human Behavior, 28(5), 1700-1707. http://dx.doi.org/10. 1016/j.chb.2012.04.009

Pempek, T. A., Yermolayeva, Y. A., \& Calvert, S. L. (2009). College students' social networking experiences on Facebook. Journal of Applied Developmental Psychology, 30(3), 227-238. http://dx.doi.org/10.1016/j. appdev.2008.12.010

Peng, S. H., \& Juan, M. S. (2011). Study on the knowledge conversation and knowledge share of colleges' students on the Facebook. KC2011 conference.

Radmacher, K., \& Azmitia, M. (2006). Are there gendered pathways to intimacy in early adolescents' and emerging adults' friendships? Journal of Adolescent Research, 21, 415-448. http://dx.doi.org/10.1177/07 43558406287402

Reis, H. T., \& Shaver, P. (1988). Intimacy as interpersonal process. In S. Duck (Ed.), Handbook of personal relationships: Theory, research, and interventions (pp. 367-389). New York: Wiley.

Ryan, T., \& Xenos, S. (2011). Who uses Facebook? An investigation into the relationship between the Big Five, shyness, narcissism, loneliness, and Facebook usage. Computers in Human Behavior, 27(5), 1658-1664. http://dx.doi.org/10.1016/j.chb.2011.02.004

Subrahmanyam, K., Reich, S. M., Waechter, N. \& Espinoza, G. (2008). Online and offline social networks: Use 
of social networking sites by emerging adults. Journal of Applied Developmental Psychology, 29(6), 420-433. http://dx.doi.org/10.1016/j.appdev.2008.07.003

Tong, S. T., van Der Heide, B., Langwell, L., \& Walther, J. B. (2008). Too much of a good thing? The relationship between number of friends and interpersonal impressions on Facebook. Journal of Computer-Mediated Communication, 13, 531-549. http://dx.doi.org/10.1111/j.1083-6101.2008.00409.x

Tsai, P. T. (2000). Interpersonal relationships. Taiwan, Kaohsiung: Fu Wen Books Co., LTD.

Wilson, R. E., Gosling, S. D., \& Graham, L. T. (2012). A review of Facebook research in the social sciences. Perspectives on Psychological Science, 7(3), 203-220. http://dx.doi.org/10.1177/1745691612442904

\section{Copyrights}

Copyright for this article is retained by the author(s), with first publication rights granted to the journal.

This is an open-access article distributed under the terms and conditions of the Creative Commons Attribution license (http://creativecommons.org/licenses/by/3.0/). 